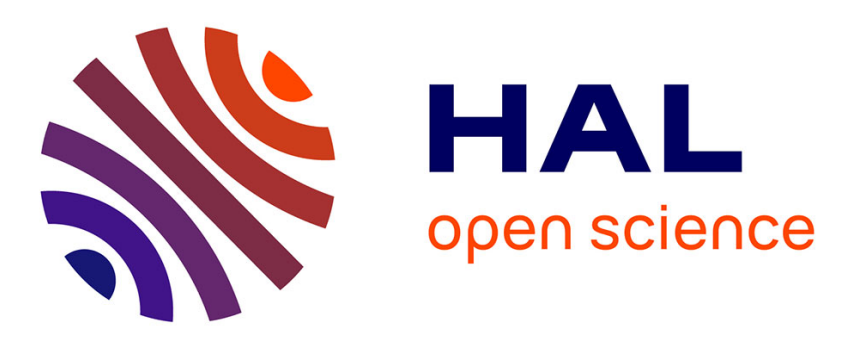

\title{
A thermal model for Phase Change Materials in a building roof for a tropical and humid climate: Model description and elements of validation
}

Stéphane Guichard, Frédéric Miranville, Dimitri Bigot, Harry Boyer

\section{- To cite this version:}

Stéphane Guichard, Frédéric Miranville, Dimitri Bigot, Harry Boyer. A thermal model for Phase Change Materials in a building roof for a tropical and humid climate: Model description and elements of validation. Energy and Buildings, 2014, 70, http://www.sciencedirect.com/science/article/pii/S0378778813007962. 10.1016/j.enbuild.2013.11.079 . hal-01000515

\section{HAL Id: hal-01000515 https://hal.science/hal-01000515}

Submitted on 4 Jun 2014

HAL is a multi-disciplinary open access archive for the deposit and dissemination of scientific research documents, whether they are published or not. The documents may come from teaching and research institutions in France or abroad, or from public or private research centers.
L'archive ouverte pluridisciplinaire HAL, est destinée au dépôt et à la diffusion de documents scientifiques de niveau recherche, publiés ou non, émanant des établissements d'enseignement et de recherche français ou étrangers, des laboratoires publics ou privés. 


\section{Submission of manuscript to Energy and Buildings}

\section{A thermal model for Phase Change Materials in a building roof for a tropical and humid climate: \\ Model description and elements of validation}

Stéphane GUICHARD, Frédéric MIRANVILLE, Dimitri BIGOT and Harry BOYER

Contents:

- Manuscript

Corresponding author:

\section{Stéphane GUICHARD}

Physics and Mathematical Engineering Laboratory for Energy and Environment (PIMENT)

University of Reunion

117, rue du Général Ailleret

97430 Le Tampon

tél : 0693132090

fax : 0262962859

email : stephane.guichard@univ-reunion.fr 


\title{
A thermal model for Phase Change Materials in a building roof for a
}

\author{
tropical and humid climate :
}

Model description and elements of validation

\author{
Stéphane GUICHARD, Frédéric MIRANVILLE, Dimitri BIGOT and Harry BOYER \\ University of Reunion, Physics and Mathematical Engineering Laboratory for Energy and Environment (PIMENT) \\ 117, rue du Général Ailleret 97430 Le Tampon, France. \\ Phone (+693) 1320 90, Fax (+262) 9628 59, email : stephane.guichard@univ-reunion.fr.
}

\begin{abstract}
This article deals with a numerical model of the thermal behaviour of a building roof equipped with phase change materials (PCM). The study puts in evidence the first results of the proposed model based on the apparent heat capacity method. A backward Euler scheme and a finite difference discretization method have been used. The model was integrated in a multizone building simulation code and is able to predict both the whole temperature of each building component and the thermal impact of PCMs installed in buildings for several configurations. A first experimental study has been conducted for a tropical and humid climate, using a full-scale outdoor test cell equipped with PCMs installed as a component of the ceiling. It allowed to give elements of validation for the numerical model, through a validation process including comparisons with measurements A sensitivity analysis has also been run to highlight the influencing parameters of the thermal model. The first results from comparisons between model predictions and measurements are encouraging and show a convenient agreement for the given configuration under field conditions.
\end{abstract}

Keywords : Phase change materials ; Thermal modeling ; Validation methodology ; Sensitivity analysis.

\section{Contents}

1. Introduction _-_________-_

2. Thermal modeling of PCMs integrated in a building simulation code_______________________________ 4

2.1. Presentation of the building simulation code $I S O L A B$

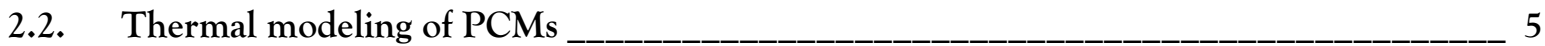

2.3. Statement of the problem and boundary conditions _________________________________ 8

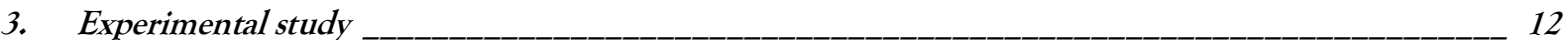

3.1. The experimental platform _________________________________________________________ 12

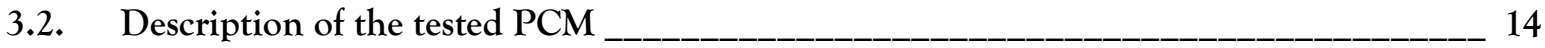

3.3. Climatic data and experimental sequences __________________________________________ 14

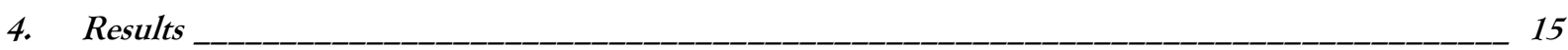

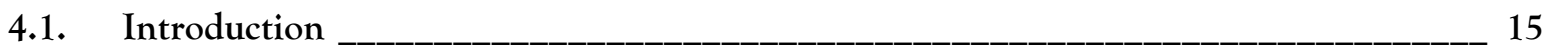

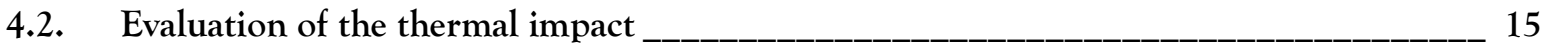

4.3. Comparison between numerical simulation and experimental data __________________ 16

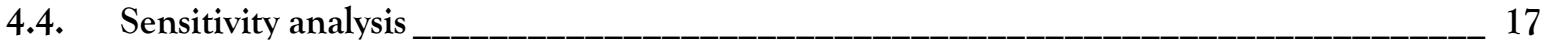

5. Conclusion and further work _____________________________________________________________ 19

6. References 


\section{Introduction}

According to the Intergovernmental Panel on Climate Change (IPCC), global warming is due to greenhouse gas emissions (mainly $\mathrm{CO}_{2}$ ). For $\mathrm{ADEME}^{1}$ organization in FRANCE, building sector represents around $25 \%$ of $\mathrm{CO}_{2}$ emissions and approximately $45.8 \%$ for the total energy consumption. Usually, the total primary energy requirements in the building sector is used for heating and airconditioning to reach thermal comfort. Technical solutions consist in using thermal insulation and new technologies to store thermal energy in order to enhance the thermal inertia. One of possible option is to use phase change materials (PCMs). A phase change material can be defined as an organic (or inorganic) compound, able to store and release the thermal energy under latent form when it changes from one physical state to another at a nearly constant temperature. In building applications, the phase changes from solid to liquid or from liquid to solid. Several investigations have been conducted by many researchers for different applications and in many countries, except until now at Reunion Island.

Reunion Island is part of the French overseas departments, characterized by a tropical and humid climate, with a strong solar radiation in summer. Despite being an ideal location for experimentations on building materials under extreme conditions,, few experimental studies have been conducted about integrating PCMs into building envelopes, in particularly the roof. The roof is the most exposed part to solar radiation during daytime and is responsible of the inside air temperature increase in buildings. One of possible solution to avoid overheating during summer is to add insulation to the roof or to use radiant barriers (RBs) as stated in [1].

Instead of blocking heat transfer through the roof, another solution is to increase its thermal inertia using PCMs. To illustrate this statement, a chosen phase change material was installed in the roof of a full scale test cell, with the presence of an upper air layer in order to take benefit of its reflective surfaces. Its characteristics were chosen to have both an interesting latent heat and a phase change temperature corresponding to the range of the experimental sequence.

\footnotetext{
${ }^{1}$ French Environment and Energy Management Agency
} 
In this article, the statement of the physical problem is described in details, and more precisely the relations describing coupled heat transfers. A comparison between numerical solutions and experimental data is illustrated, corresponding to the first step of the validation process of the thermal model. Then, a sensitivity analysis is presented in order to identify the most important parameters that influence the thermal model results.

\section{Thermal modeling of PCMs integrated in a building simulation code}

\subsection{Presentation of the building simulation code ISOLAB}

ISOLAB was developed by Pr. F. MIRANVILLE during his Ph.D thesis [2]. It is a building simulation code able to predict energetic behavior using numerical simulations, and developed with MATLAB platform. ISOLAB is based on a nodal description of buildings with a one-dimensional modeling of the thermal phenomena arising in the walls and zones comprising the building. It is able to simulate the temperature and flux fields of monozone and multi-zone buildings according to its location and climate. Usually, ISOLAB is dedicated to test models before integration in the building simulation software CODYRUN, developed and distributed at the Physics and Mathematical Engineering Laboratory for Energy and Environment of the University of Reunion [3,4]. The building thermal model used by ISOLAB is based on the discretization of the transient heat transfer equation (1) :

$$
\begin{gathered}
\text { Where: }\left\{\begin{array}{l}
\alpha=\frac{1}{\alpha} \frac{\partial T}{\partial t}-\frac{P}{\lambda} \\
P \text { internal heat power generated }
\end{array}\right.
\end{gathered}
$$

The building is decomposed into walls that contain several nodes. For each node, the transient heat transfer equation is discretized using the finite difference method [1]. This discretization leads to a matrix equation system that describes the transient heat transfer equation of each node. Finally, the matricial system obtained can be written in the form:

$$
[T]_{i}^{t}=[A]_{e}[T]_{i}^{t+\Delta T}+[B]_{i}^{t+\Delta T}
$$

With: 
- Matrix $[A]_{e}$ including terms for conductive, convective and radiative models as well as the various materials constituting the building.

- Vector $[B]$ corresponding to outside or internal solicitations of the studied system.

- Vectors $[T]^{t}$ and $[T]^{t+\Delta t}$ containing all temperatures nodes of each wall for two successive time steps $(t$ and $t+\Delta t)$.

The evolution of the building temperature field is obtained by solving the equation system (2) for each time step of the meteorological database of the environment where the building is located. The temperature field at time step $t+\Delta t$ is obtained by using the following relation:

$$
[T]_{i}^{t+\Delta t}=\left([T]_{i}^{t}-[B]_{i}^{t+\Delta T}\right) \cdot[A]_{e}^{-1}
$$

ISOLAB code wasn't able to model PCM walls before this work. For this reason, the PCM numerical model presented in this paper was developed and integrated to ISOLAB. To successfully integrate the building simulation code, the PCM model was elaborated respecting the state system formalism and using a backward Euler scheme. Next paragraph will present the thermal model of PCM.

\subsection{Thermal modeling of PCMs}

Among thermal models of PCMs in the literature, we chose the apparent specific heat capacity method [5]. The main advantage of this method is to allow non-tracking the interface. Furthermore, this method is in accordance with the formalism of ISOLAB equations and, from the literature, good results have already been obtained using it. In our approach, the mathematical formulation presented is based on some assumptions, such as:

(H1) All heat transfer modes are one-dimensional and taken into account for each wall of the building, also including PCM panels ;

(H2) Thermal properties of PCMs are considered not constant ;

(H3) The combined effect of radiation and convection in PCMs are neglected;

(H4) The specific heat capacity $\mathrm{C}_{\mathrm{p}}$ is supposed known for each phase region, particularly during the solid-liquid phase change, and considered as a constant value being given by DSC (Differential Scanning Calorimeter). However, its evolution is supposed to be unknown during 
time. This assumption allows the evaluation of the model performance to predict the thermal behavior of a phase change material if the DSC is not known ;

(H5) The internal heat power generated is neglected;

(H6) The thermal conductivity do not vary according to space ;

(H7) Stored and released energy during the phase change are supposed to be of the same amount ;

By taking into account these assumptions, only heat conduction will be considered and the transient local equation of the energy balance under enthalpy form can be written in 1-D along the $\vec{x}$ direction as:

$$
\frac{\partial H(x, t)}{\partial t}=\lambda_{P C M}(T) \frac{\partial^{2} T(x, t)}{\partial x^{2}}
$$

$H$ refers to the enthalpy and is defined by:

$$
H(x, t)= \begin{cases}\rho_{s} c_{s}\left(T(x, t)-T_{m}\right) & \text { if } T(x, t) \leq T_{m} \\ \rho_{l} c_{l}\left(T(x, t)-T_{m}\right)+\rho_{l} L_{m} & \text { if } \quad T(x, t) \geq T_{m}\end{cases}
$$

$H$ can still be written in terms of solid fraction $f_{S}$ :

$$
H(T)=\left[\left(1-f_{s}\right) \rho_{s} c_{s}+\rho_{l} c_{l} f_{s}\right]\left(T(x, t)-T_{m}\right)+\rho_{l} L_{m}
$$

$$
\text { Where: }\left\{\begin{array}{l}
f_{s}=0: \text { completely solid phase } \\
f_{s}=1: \text { completely liquid phase }
\end{array}\right.
$$

By replacing $H$ by its expression in (4), the final expression of transient heat equation is $[6,7]$ :

$$
\begin{gathered}
C_{a p p}(T) \frac{\partial T(x, t)}{\partial t}=\lambda_{P C M}(T) \frac{\partial^{2} T(x, t)}{\partial x^{2}} \\
\text { With: }\left\{\begin{array}{c}
C_{a p p}(T)=\rho_{s} c_{s}+\Delta(\rho c)+\frac{d f_{s}(T)}{d T}\left(\rho_{l} L_{m}+\Delta(\rho c) .\left(T(x, t)-T_{m}\right)\right) \\
\Delta(\rho c)=\rho_{l} c_{l}-\rho_{s} c_{s} \\
\lambda_{P C M}(T)=\left(1-f_{s}(T)\right) \lambda_{s}+\lambda_{l} f_{s}(T)
\end{array}\right.
\end{gathered}
$$

\subsubsection{Expression of the solid fraction}

In the literature $[6,7,8,9]$, the solid fraction is defined through the Heaviside function $\mathcal{H}$ :

$$
f_{s}(T)=1-\mathcal{H}\left(T(x, t)-T_{m}\right)
$$


At $T=T_{m}$, the derivative of the Heaviside function tends to infinity. The expression of used solid fraction is based on an approximation of the Heaviside function obtained by the approach of the sigmoid function [7] and is defined by:

$$
f_{s}(T)=\frac{1}{2}-\frac{1}{2} \tanh \left(\gamma \frac{T_{m}-T(x, t)}{4 \delta T}\right)
$$

$\delta T$ is the temperature range over which the phase change occurs and chosen often very small in order to ensure phase change at a given temperature. Usually, $\gamma$ is taken equal to 1 [6] but this parameter looks like a non-dimensional velocity of phase change and its value must be determined in order to observe the real phenomena. Different values of $\gamma$ was used and presented in [7]. Furthermore, the expression of the equation (7), when $\gamma$ tends to infinity corresponds to Heaviside function, but in physics this one must be finite. This parameter will influence on the derivative gradient of the solid fraction. Its maximal value is evaluated during the phase change at $T=T_{m}$. For a given phase change interval, we have the following process [9]:

If $T(x, t) \geq T_{m}-\delta T$ and $T(x, t) \leq T_{m}+\delta T$ then

$\mid \max (\gamma)=\left(\max \left(C_{D S C}\right)-\left(\frac{c_{s}+c_{l}}{2}\right)\right) \cdot \frac{8 \delta T}{L_{m}}$

else

$\mid \gamma$ must be determined

end

This maximal value must be determined to ensure the maximal latent heat. Therefore, the latent heat value from DSC analysis will not be underestimated or overestimated. In our case, $\delta T=0.01^{\circ} \mathrm{C}$.

\subsubsection{Numerical methods}

The phase change problem is solved by finite difference method and using a backward Euler scheme. $T_{i}^{t}$ is the temperature at the node $x_{i}=i \Delta x$ and at the time $t_{t}=t \Delta t$, where the space step $\Delta x$ and the time step $\Delta t$ are taken as constant. The temporal partial derivative term is given by a first-order scheme:

$$
\frac{\partial T(x, t)}{\partial t}=\frac{T_{i}^{t+\Delta t}-T_{i}^{t}}{\Delta t}
$$


The space partial derivative term is approximated as follows:

$$
\begin{aligned}
\lambda(T) \frac{\partial^{2} T(x, t)}{\partial x^{2}}= & \frac{\lambda\left(T_{i+1}^{t+\Delta t}\right)+\lambda\left(T_{i}^{t+\Delta t}\right)}{2} \frac{T_{i+1}^{t+\Delta t}-T_{i}^{t+\Delta t}}{\Delta x^{2}} \\
& -\frac{\lambda\left(T_{i-1}^{t+\Delta t}\right)+\lambda\left(T_{i}^{t+\Delta t}\right)}{2} \frac{T_{i}^{t+\Delta t}-T_{i-1}^{t+\Delta t}}{\Delta x^{2}}
\end{aligned}
$$

According to an implicit scheme and by applying the finite difference method on the transient heat transfer equation, we have a discrete form as follows:

$$
\begin{gathered}
\left(1-\xi_{3}\right) T_{i}^{t+\Delta t}+\xi_{1} T_{i+1}^{t+\Delta t}+\xi_{2} T_{i-1}^{t+\Delta t}=T_{i}^{t} \\
\text { With : }\left\{\begin{array}{l}
\xi_{1}=-\frac{\Delta t\left[\lambda\left(T_{i+1}^{t+\Delta t}\right)+\lambda\left(T_{i}^{t+\Delta t}\right)\right]}{2 C_{a p p}\left(T_{i}^{t+\Delta t}\right) \Delta x^{2}} \\
\xi_{2}=-\frac{\Delta t\left[\lambda\left(T_{i-1}^{t+\Delta t}\right)+\lambda\left(T_{i}^{t+\Delta t}\right)\right]}{2 C_{a p p}\left(T_{i}^{t+\Delta t}\right) \Delta x^{2}} \\
\xi_{3}=\xi_{1}+\xi_{2}
\end{array}\right.
\end{gathered}
$$

If the layer is homogenous and the thermal-physical properties are not function of temperature, we solve the classical heat transfer equation:

$$
\left\{\begin{array}{c}
\xi_{1}=\xi_{2}=-\frac{\lambda \Delta t}{\rho C_{p} \Delta x^{2}} \\
\xi_{3}=1-\xi_{1}
\end{array}\right.
$$

The PCM model consists in assembling the conductive, convective and radiative models leading to the following equation system (according to equation (3)):

$$
\left[T_{P C M}\right]_{i}^{t}=\left[A_{P C M}\right]_{e}\left[T_{P C M}\right]_{i}^{t+\Delta T}+\left[B_{P C M}\right]_{i}^{t+\Delta T}
$$

It should be noticed that the presented thermal model has already been compared to analytical solutions (cases of infinite and finite domains) from literature and from COMSOL software for simplified cases [7,9].

\subsection{Statement of the problem and boundary conditions}

The considered physical system is a complex roof integrating PCM panels. A new type of configuration is suggested to allow the charging and discharging process of energy in PCM (see figure 1(a)). Usually, the charging process corresponds to transition from solid to liquid and is called melting. During this phase, energy is absorbed. At night, PCM discharges the energy stored during the sunshine hours and its phase changes from liquid to solid; this part corresponds to the solidification 
phenomenon. Between the corrugated iron of the roof top and the ceiling, an air layer is installed. The complex roof assembly is based on previous works of the laboratory of typical complex walls including radiant barriers $(\mathrm{RB})[2,10]$. In our approach, the air-gap is not ventilated and the test cell is divided into two zones by the ceiling, as showed on figure 1(c). The corrugated iron was painted with a dark blue color, allowing reaching extreme solicitations on the outer surface of the complex wall. Solicitations are due to forced convection (wind effects) and radiation. On the inner surface of wallboard, the convection was considered to be natural.

\section{Figure 1: Presentation of studied case}

On the figures $1(\mathrm{a})$ and $1(\mathrm{~b})$, by considering boundary conditions on the exterior surface of a wall at $x=L_{4}$, the energy balance for a slice of thickness $\frac{\Delta x}{2}$ is given by (14) [2,9]:

$$
\begin{gathered}
\varphi_{C D, \text { out }}+\varphi_{s w r, \text { out }}+\varphi_{\text {lwr,out }}+\varphi_{C V, \text { out }}=\rho_{9} C_{p 9} \frac{\Delta x_{9}}{2} \frac{d T_{s e, w}}{d t} \\
\text { With: }\left\{\begin{array}{c}
\varphi_{C D, \text { out }}=\frac{\lambda_{9}}{\Delta x_{9}}\left(T_{8}-T_{s e, w}\right) \\
\varphi_{l w r, \text { out }}=H_{p c}\left(T_{s k y}-T_{s e, w}\right)+H_{p e}\left(T_{e n v}-T_{s e, w}\right) \\
\varphi_{s w r, \text { out }}=\alpha_{p} E \\
\varphi_{C V, \text { out }}=h_{c e, C i}\left(T_{\text {env }}-T_{s e, w}\right)
\end{array}\right.
\end{gathered}
$$

$h_{c e, C i}$ is calculated by a correlation as follows:

$$
h_{c e, C i}=a+b V^{n}
$$

\section{Where: $\left\{\begin{array}{l}a, b \text { and } n \text { are constant coefficients given by the chosen empirical model } \\ V \text { is the wind speed }\end{array}\right.$}

Finally, we have:

$$
\begin{gathered}
T_{s e, w}^{t}=T_{9}^{t}=\left[1+\frac{2 \Delta t}{\tau}+\frac{2 \Delta t}{C}\left(h_{c e, C i}+H_{p c}+H_{p e}\right)\right] T_{9}^{t+\Delta t} \\
-\frac{2 \Delta t}{\tau} T_{8}^{t+\Delta t}-\frac{2 \Delta t}{C}\left(h_{c e, C i}+H_{p e}\right) T_{a e} \\
-\frac{2 \Delta t}{C} H_{p e} T_{s k y}^{t+\Delta t}-\frac{2 \Delta t}{C} \alpha_{p} E_{s w r}^{t+\Delta t}
\end{gathered}
$$


For the monozone case, at $x=0$ and making the assumption that the shortwave radiation is neglected (solar radiation is unable to get into the test cell) [9], the energy balance for an interior surface of a zone is written as follows:

$$
\begin{gathered}
\varphi_{C D, \text { in }}+\varphi_{l w r, i n}+\varphi_{C V, i n}=\rho_{1} C_{p 1} \frac{\Delta x_{1}}{2} \frac{d T_{s i, w}}{d t} \\
\text { With: }\left\{\begin{array}{l}
\varphi_{C D, i n}=\frac{\lambda_{1}}{\Delta x_{1}}\left(T_{2}-T_{s i, w}\right) \\
\varphi_{l w r, i n}=h_{r i, Z_{1}}\left(T_{r m, i n}-T_{s i, w}\right) \\
\varphi_{C V, i n}=h_{c i, w}\left(T_{a i, i n}-T_{s i, w}\right)
\end{array}\right.
\end{gathered}
$$

$h_{c i, w}$ is determined as the equation (19) correlation. The discretized equation is:

$$
\begin{gathered}
T_{s i, w}^{t}=T_{1}^{t}=\left[1+\frac{2 \Delta t}{\tau}+\frac{2 \Delta t}{C}\left(h_{c i, w}+h_{r i, Z_{1}}\right)\right] T_{1}^{t+\Delta t}-\frac{2 \Delta t}{\tau} T_{2}^{t+\Delta t} \\
-\frac{2 \Delta t}{C} h_{c i, w} T_{a i, i n}^{t+\Delta t}-\frac{2 \Delta t}{C} h_{r i, Z_{1}} T_{r m, i n}^{t+\Delta t}
\end{gathered}
$$

However, at $=L_{2},\{$ wallboard $+P C M\}$ system is a specific wall because it is an interzone or a partition wall between two adjacent zones. Indeed, on one hand it will be considered as a suspended ceiling (zone 1) and on the other hand as a floor (zone 2). So, the energy balance from equation (21) is:

$$
\varphi_{C D, z a d j}+\varphi_{l w r, z a d j}+\varphi_{C V, z a d j}=\rho_{5} C_{p 5} \frac{\Delta x_{5}}{2} \frac{d T_{s e, w}}{d t}
$$

$$
\begin{aligned}
& \text { With: }\left\{\begin{array}{c}
\varphi_{C D, z a d j}=\frac{\lambda_{5}}{\Delta x_{5}}\left(T_{4}-T_{s i, w}\right) \\
\varphi_{l w r, z a d j}=h_{r i, z a d j}\left(T_{r m, z a d j}-T_{s i, w}\right) \\
\varphi_{C V, \text { zadj }}=h_{c i, z a d j}\left(T_{a i, z a d j}-T_{s i, w}\right)
\end{array}\right. \\
& T_{s e, w}^{t}=T_{5}^{t}=\left[1+\frac{2 \Delta t}{\tau}+\frac{2 \Delta t}{C}\left(h_{c i, z a d j}+h_{\text {ri,zadj } j}\right)\right] T_{5}^{t+\Delta t} \\
& -\frac{2 \Delta t}{\tau} T_{4}^{t+\Delta t}-\frac{2 \Delta t}{C} h_{c i, z a d j} T_{a i, z a d j}^{t+\Delta t} \\
& -\frac{2 \Delta t}{C} h_{r i, z a d j} T_{r m, z a d j}^{t+\Delta t}
\end{aligned}
$$

Assuming conductive heat fluxes defined as follows:

$$
\left\{\begin{array}{l}
\varphi_{C D, i, b}=\frac{\lambda_{i}}{\Delta x_{i}}\left(T_{i-1}^{t+\Delta t}-T_{i}^{t+\Delta t}\right) \\
\varphi_{C D, i, a}=\frac{\lambda_{i+1}}{\Delta x_{i+1}}\left(T_{i+1}^{t+\Delta t}-T_{i}^{t+\Delta t}\right)
\end{array}\right.
$$


For a good integration of the PCM model and a successful coupling with ISOLAB, some points should not be forgotten, such as:

1. To take into account convective exchanges inside the air-gaps by integrating a thermo-convective energy balance for each air-gap;

2. To take into account convective exchanges inside the building by coupling the conductive model of PCM wall and the thermo-convective energy balance of the zone where it is installed;

3. To link the conductive model of PCM wall with the radiative energy balance of the zone;

4. To take all boundary conditions of specifics walls and others.

The coefficients due to the radiation exchanges noted $h_{r i, Z_{1}}$ and $h_{r i, Z_{2}}$ for the two zones are unchanging and equal to $5 \mathrm{~W} \cdot \mathrm{m}^{-2} \cdot \mathrm{K}^{-1}$, which is a mean value from the work of [2]. On the outer surface of corrugated iron, the coefficient due to forced convection effect is taken into account by using the local experimental correlation that was developed by MIRANVILLE [2] :

$$
h_{c e, C i}=5.7 \mathrm{~V}+11.4 \text { for a windward wall }
$$

For the first simulations, as we wanted to evaluate other convection coefficient values without correlations, the constant values given by the following Table 1 were used (see [2]):

Table 1: Reference value used for the first numerical solutions

\subsubsection{Description of MCPbat in ISOLAB code environment}

The thermal model developed is called MCPbat [9]. MCPbat is able to predict the thermal field of PCM panels integrated in building envelopes and was coupled with ISOLAB code. The addition of the PCM panel model to ISOLAB is made like a complex multi layer wall. A complex wall can be defined as an assembly of materials, separated by one or several air layers [2]. MCPbat offers a detailed description for each PCM components of building envelope in order to calculate the building thermal field. If PCM panels are integrated into the building envelope, all of their properties are described according to 
thermo-physical and geometrical parameters, as well as the type of integration. In fact, the PCM model considers every kind of possible integration as represented on the figure 2 .

Figure 2: Integration of the PCM model to the existing ISOLAB code.

The PCM model has the advantage of being completely generic from a thermal point of view. By using a meteorological database associated to the building physical and structural description, the simulation can be run. During the simulation, when the ISOLAB code detects a PCM panel installed on the building, MCPbat is used to generate the matrix describing thermal exchanges through the PCM panel. This matrix is added to the traditional matrix system of the whole building [1].

After assembly of the PCM matrixes with the building matrix generated by ISOLAB, the final equation for the whole system is :

$$
[T]_{i}^{t}=[A]_{e}[T]_{i}^{t+\Delta T}+[B]_{i}^{t+\Delta T}
$$

This equation is solved as described in equation (2). Even if the ISOLAB code was already validated with well recognized methods like those of the IEA BESTEST (International Energy Agency for Building Energy Simulation Test) [2,11], the PCM model (MCPbat) required a validation step. This validation was made by using an experimental study on a full-scale outdoor test-cell integrating PCMs. As PCMs are distributed under a flexible sheet form, their integration was made as a component of the suspended ceiling [9].

\section{Experimental study}

\subsection{The experimental platform}

The experimental platform has been set up at the south of Reunion Island, more precisely at the University of Technology of Saint-Pierre, at a low altitude from the sea level $(55 \mathrm{~m})$. The choice of this location corresponds to the needs of a tropical climate with strong solar radiation and humidity. These climate conditions offer ideal characteristics for such an experimental study. 
This platform is composed of different test cells, some of them being low scale devices (called ISOTEST) and another one a normal scale (or unit scale) building (called LGI) $[2,9,12]$ (see figure 3).

Figure 3: Photo of ISOTEST and LGI test cell.

On the experimentation platform, two meteorological stations are also installed allowing to precisely collect meteorological data near to the experimental devices. The two meteorological stations allow to control the quality and validity of the obtained data.

The different test cells on the experimental platform are oriented facing the geographical north in order to receive symmetrical solar solicitations during the day. No shading occurs from one test cell to another, in order to ensure that interactions between the cells are negligible.

\subsubsection{Details of the LGI test cell used for the experiment.}

The LGI test cell can be considered as a typical room of a building. It has an interior volume of about $30 \mathrm{~m}^{3}$ and is designed with a modular structure, which allows testing several configurations and physical phenomena. It features opaque vertical walls, with blind-type windows, a glass door and a specific roof containing PCMs. The details of the arrangement of the LGI test cell are given in Table 2.

Table 2: Arrangement of the LGI test cell

All glazing from the windows and the door were masked as depicted on figure 3 [9]. Roof is inclined at $20^{\circ}$ to the horizontal representing the angle of inclination frequently encountered in Reunion Island.

\subsubsection{Instrumentation of LGI test cell}

The LGI cell is equipped with many sensors, located in the two zones. The sensors located in zone 1 are thermal ones placed at each side of each wall (north, south, east and west) and the interior air volume is monitored at three different levels from the floor to the ceiling, in order to put in evidence the effect of air stratification. To determine the boundary conditions from the floor, thermocouples are 
sealed in the concrete floor of the LGI test cell. Some thermocouples are also inserted in an aluminum cylinder for air temperature measurements and in a black globe to measure the radiant temperature. The same type of thermocouple is also placed on both side of complex roof (type T).

Before using each thermocouple, they have been verified and calibrated on site. The other sensors were also verified by the supplier. Generally, the accuracy from the thermocouples is approximately about $\pm 0.1{ }^{\circ} \mathrm{C}$ and the accuracy of the heat flux meter is $5 \%$. To avoid air bubbles during installation and resulting errors, a conductive heat paste was applied on the surface of the flux meter.

To collect data, all sensors was connected to a datalogger (Campbell Scientific CR23X) located in the LGI cell. Every quarter-hour, the data were collected and saved on a dedicated computer.

\subsection{Description of the tested PCM}

PCM tested is the commercial product from Dupont ${ }^{\mathrm{TM}}$ Energain ${ }^{\circledR}$. It is a flexible sheet of $5 \mathrm{~mm}$ thickness constituted of $60 \%$ microencapsulated paraffin wax within a copolymer laminated on both sides with an aluminum sheet. Its characteristics are summarized in the following Table 3:

\section{Table 3 : Characteristics of PCM used}

Values of the heat capacity in each phase and melting point have been determined by DSC measurements. These parameters are exposed in details in $[13,14]$

\subsection{Climatic data and experimental sequences}

Two meteorological stations were set up on the area to collect climatic database for the experimental sequences. Mainly, the collected meteorological database contained the solar radiation (global, direct and diffuse, on a horizontal plane), the wind speed and direction, the air temperature and the exterior relative humidity rate. These data were used by the building simulation code to predict the building thermal behavior.

This experimental study was conducted on two months, from August to October 2012. The climatic conditions correspond to the typical season before beginning of the summer season in Reunion Island. These data are given by the figure 4 . 
The choice of this period ensures melting temperature and allows regenerating the PCM. The chosen experimental sequence corresponds to five days, precisely from $20^{\text {th }}$ September to $24^{\text {th }}$ September 2012.

Figure 4: The climatic conditions during experimental period

\section{Results}

\subsection{Introduction}

In order to validate the PCM numerical thermal model and the correct implementation of MCPbat in ISOLAB, different steps were run $[1,9,12]$. Among them, only two steps are presented and consist in:

1. Comparing the model results and measurements;

2. Leading a sensitivity analysis when simulation results do not match measurements and the validity criterion is not respected, in order to determine the most influential parameters on the model outputs ;

The PCM model can be validated, if and only if, the validation criteria (CVal) is respected during the comparison between measurements and predictions. The validity criteria for the PCM model has been chosen as the following formula:

$$
C v a l=\frac{T_{\text {data }}-T_{\text {model }}}{\max \left(T_{\text {data }}\right)-\min \left(T_{\text {data }}\right)} \times \frac{10}{100}
$$

We note that temperatures for the floor are used as boundary conditions (imposed to measured value) for the corresponding nodes because this part of the building requires a $2 \mathrm{D}$ model discretization. In our case, modeling with one dimensional was made. That's why the floor temperature was supposed known and given by the experimental data.

\subsection{Evaluation of the thermal impact}

To evaluate the thermal impact of PCMs on the test cell, a comparison between numerical solutions without PCM and the measurements with PCM is made. As depicted in figure 5, the inside air temperature without PCM is more higher than the inside air temperature with PCM. The difference 
between two temperatures reaches a maximum of $2.4^{\circ} \mathrm{C}$. Furthermore, the presence of PCMs implies a delay in the temperature rise. This is justified by the increase of the thermal inertia of the roof through the storage and release of energy. So, the thermal behaviour of PCMs allows to reduce the amplitude of temperatures between minimal and values. This result is interesting because it illustrates the contribution of the PCM to improve the thermal comfort within the test cell. These first results confirm our expectations of the added insulation effect by using PCMs.

Figure 5: Thermal impact of PCM on the inside air temperature of the building

However, these results must be completed with other experimental studies in order to definitely confirm the use of these materials at Reunion Island. Indeed, to experimentally validate our results, two same real physical building should be erected, one with PCM and another one without PCM. A preliminary study can be made before, by using numerical simulations with ISOLAB code in order to determine the optimal configuration. For this, the numerical thermal model of PCMs must be validated with experimental data.

\subsection{Comparison between numerical simulation and experimental data}

The first step consists in comparing the numerical model with experimental data by using the different parameters from literature in order to approach the real parameters values. These values have already been discussed in detail [9].

For instance and as represented on figure 6 , despite the good dynamic behavior predicted by numerical simulations, there are some differences between the model and the measurements from the experimentation. Furthermore, the validation criteria, as mentioned above, are not respected.

Figure 6: Comparison between numerical solution and experimental data for the surface temperature of plasterboard and air temperature within test cell.

Another very interesting result is the prediction of inside air of the test cell. As depicted on figure 6(d), we can see that the proposed model is able to predict the measurements with a precision of $\pm 1^{\circ} \mathrm{C}$. 
However, we can again notice that the criterion is not respected, but the thermal model is in agreement with the expected results.

To explain origins of errors, a sensitivity analysis was made and the unknown parameters were identified $[1,9,12]$.

\subsection{Sensitivity analysis}

As mentioned in the step one, some errors between numerical simulation and experimental data was noticed. It is important to determinate origins of errors (parameter error or modeling error ?), and that's why a study of the most important parameters influencing the model results was conducted [1]. The sensitivity analysis highlighted the parameters that are responsible of errors between measurements and predictions.

The sensitivity analysis is based on the FAST (Fast Fourier Amplitude Transform) method, and allows determining the most influential parameters on one or several outputs from a model for variations of the parameters around some base value. By using a sinusoidal sample, all parameters vary around their base values. For more details, the interested reader can refer to $[1,12,15,16]$. To sum up and as shown on figure 7, the general procedure can be described as follows : a frequency is attributed to each parameter; from a simulation to another and for a given number of simulations, each parameter is changed according to a sinusoidal variation around a based value. All results of each simulations is saved as a large matrix. By doing a Fourier analysis on the final matrix, the most influent parameters can be determined by reading their frequency, which appear like peaks on the spectrum.

Figure 7 : Procedure of sensitivity analysis

To evaluate the most influent parameters of the proposed model, it is convenient to define the variation intervals for the different parameters. Usually, this variation is given as a percentage variation around a base value. In this paper, a variation between $10 \%$ and $50 \%$ was applied on all parameters of the PCM model and the building (geometrical, convective and radiation coefficients, thermo-physical properties of PCM panel and others building envelopes materials), representing a total of 228 
parameters. However, the method requires more than twice the number of parameters in simulations, thus 456 simulations were necessary.

The analysis is presented for the first three days of measurements in order to not overload the graph. As an example, based on the Fourier spectrum, figure 8 illustrates the parameters that were identified as the most influential parameters on the air-gap temperature (see Table 4).

Figure 8: Results of the sensitivity analysis for the air-gap temperature (zone 2)

Table 4: Most influential parameters on the air-gap temperature.

All parameters must not be optimized because their value are known. In fact, all geometrical properties of each building wall has been measured such as plasterboard surface for example. In addition to these parameters and for all layers of the complex roof, all convective exchange coefficients on both sides of the complex roof and the $\gamma$ coefficient were identified. Among these parameters, the most important parameters are the absorptivity and exterior convective exchange coefficient of the metal sheet. With reference to the outside surface temperature of the PCM panel, thermo-physical properties such as latent heat, melting temperature, solid heat capacity and solid heat density and the $\gamma$ coefficient were identified as most influential parameters. However, except the $\gamma$ coefficient, others parameters are given by DSC analysis.

To summarize, the parameters that have to be optimized to predict the thermal temperature of roof components are given in Table 5 :

Table 5 : Most influential parameters at the end of sensitivity analysis.

These results were expected because all convective exchange coefficients were not well known and values chosen from the literature. They were identified as influential because the suspended ceiling is in contact with the air layer. , A natural convection transfer is thus set up because the test cell is kept closed and the air layer is non-ventilated. The value of absorptivity coefficient of the metal sheet from [2] must be determined because the thermal performances have changed. By using a constant value for the 
outdoor convective exchange coefficient, the given result as also expected. Indeed, as the wind speed was not taken into account, the prediction of temperature field of corrugated iron led to errors between numerical solutions and measurements. $\gamma$ coefficient has been chosen arbitrary and plays an important role on the derivative gradient of the solid fraction. $\gamma$ coefficient can thus be physically interpreted as a non-dimensional velocity of phase change, because the maximal value of this parameter is low. Indeed and according to the theory, the phase change process occurs for very small velocity that corresponds to $\gamma$ value.

However, to improve the model it is necessary to evaluate the unknown parameters that influence the thermal model and that was identified by the sensitivity analysis. To definitely validate the model three steps will be required corresponding to :

1. an optimization sequence to determinate the unknown parameters;

2. confront the optimized model with measurements for the chosen experimental sequence;

3. confront the optimized model with measurements for another experimental sequence; These steps will be presented in a coming paper.

\section{Conclusion and further work}

The aim of this article was to provide reliable experimental data in order to validate a new generic thermal model of PCMs in building. An actual size test cell was used to measure the multi layer temperatures of the complex roof and the inside air temperature in field conditions. A detailed investigation has been carried out to evaluate the efficiency of the thermal behaviour of the model, with important steps included in experimental validation.

A mathematical model was presented, based on a nodal description of the complex wall and solved using finite difference in one-dimension. In order to validate the numerical model, two steps of validation were presented. The first step consists in comparing the thermal model with experimental data and the second one to made a sensitivity analysis sequence. In the first step, the results show that the validation criteria was not respected. However, errors between theory and experimental could be 
minimized and that's why it is necessary to identified the most important parameters that influence the mode results.

Through a sensitivity analysis, the most influent parameters have been identified and allowed to explain the difference between predictions and measurements. Mainly, these parameters are convective exchange coefficients and a specific parameter of PCM model. It has been proved that this $\gamma$ coefficient plays an important role in the predictions and should be chosen precisely. Therefore, if the heat apparent capacity method is used, it is important to study this parameter.

The results presented in this article are very promising. To improve and validate the thermal model, other steps must be run. These important steps will be presented in a coming paper. 


\section{References}

[1] Bigot D., Miranville F., Boyer H., Guichard S., Jean A., Model optimization and validation with experimental data using the case of study equipped with photovoltaic panel on roof : Coupling of the building thermal simulation code ISOLAB with the generic optimization program GenOpt. Energy and Buildings, Volume 58 Issue 0, ISSN : 0378-7788, pp. 333-347, 2013.

[2] Miranville F., Contribution à l'Etude des Parois Complexes en Physique du Bâtiment : Modélisation, Expérimentation et Validation Expérimentale de Complexes de Toitures incluant des Produits Minces Réfléchissants en Climat Tropical Humide, Ph.D.Thesis : University of Reunion, 2002.

[3] Boyer H., Chabriat J., Grondin-Perez B., Tourrand C., Brau J., Thermal building simulation and computer generation of nodal models, Building and Environment, Volume 31 Issue 3, ISSN : 0360 1323, pp. 207-214, 1996.

[4] Boyer H., Garde F., Gatina J., Brau J., A multimodel approach to building thermal simulation for design and research purposes, Energy and Buildings, Volume 28 Issue 1, ISSN : 0378-7788, pp. 71 $78,1998$.

[5] Voller VR., Swaminathan CR., Thomas BG., Fixed grid techniques for phase change problems: a review, Wiley Online Library, Volume 30 Issue 4, pp. 875-898, 1990.

[6] Dauvergne J-L., Réduction et inversion de problèmes de diffusion thermique avec changement de phase. Ph.D.Thesis : University of Bordeaux I, 2008.

[7] Guichard S., Miranville F., Boyer H., A mathematical model of Phase Change Materials (PCMs) used in buildings. IASTED conference, Gaborone, Botswana, 2010.

[8] Guiavarch A., Bruneau D., Dauvergne J-L, Del Barrio E.P., Peuportier D., Clottes F., Intégration d'un modèle simplifié de matériau à changement de phase dans une plate-forme d'aide à la conception énergétique de bâtiments. 2008.

[9] Guichard S., Contribution à l'étude des parois complexes intégrant des matériaux à changement de phase : Modélisation, expérimentation et évaluation de la performance énergétique globale., Ph.D. thesis, University of Reunion, 2013.

[10] Miranville F., Fakra A.H., Guichard S., Boyer H., Praene J-P., Bigot D., Evaluation of the thermal resistance of a roof-mounted multireflective radiant barrier for tropical and humid conditions : Experimental study from field measurements, Energy and Buildings, Volume 48 Issue 0, ISSN : 0378 7788, pp. 79-90, 2012. 
[11] Judkoff R., Neymark J., International energy agency building energy simulation test (bestest) and diagnostic method, National Renewable Energy Lab., Golden, CO (US), 1995.

[12] Bigot D., Contribution à l'étude du couplage énergétique enveloppe/système dans le cas de parois complexes photovoltaïques (pc-pv), Ph.D. thesis, University of Reunion, 2011.

[13] Kuznik F., Virgone J., Experimental investigation of wallboard containing phase change material : Data for validation of numerical modeling, Energy and Buildings, Volume 41 Issue 5, ISSN : 0378-7788, pp. 561-570, 2009.

[14] David D., Kuznik F., Roux J-J., Numerical study of the influence of the convective heat transfer on the dynamical behaviour of a phase change material wall, Applied Thermal Engineering, Volume 31 Issue 16, ISSN : 1359-4311, pp. 3117-3124, 2011.

[15] Mara T.A, Garde F., Boyer H., Mamode M., Empirical validation of the thermal model of a passive solar cell test, Energy and Buildings, Volume 33 Issue 6, ISSN : 0378-7788, pp. 589-599, 2001.

[16] Mara T.A, Boyer H., Garde F., Parametric sensitivity analysis of a test cell thermal model using spectral analysis, ASME Journal of Solar Energy Engineering, Volume 124, pp. 237-242, 2002. 


\section{Submission of manuscript to Energy and Buildings}

\section{A thermal model for Phase Change Materials in a building roof for a tropical and humid climate:}

Model description and elements of validation

Stéphane GUICHARD, Frédéric MIRANVILLE, Dimitri BIGOT and Harry BOYER

Contents:

- List of figures

Corresponding author:

\section{Stéphane GUICHARD}

Physics and Mathematical Engineering Laboratory for Energy and Environment (PIMENT)

University of Reunion

117, rue du Général Ailleret

97430 Le Tampon

tél : 0693132090

fax : 0262962859

email : stephane.guichard@univ-reunion.fr 


\section{List of figures}

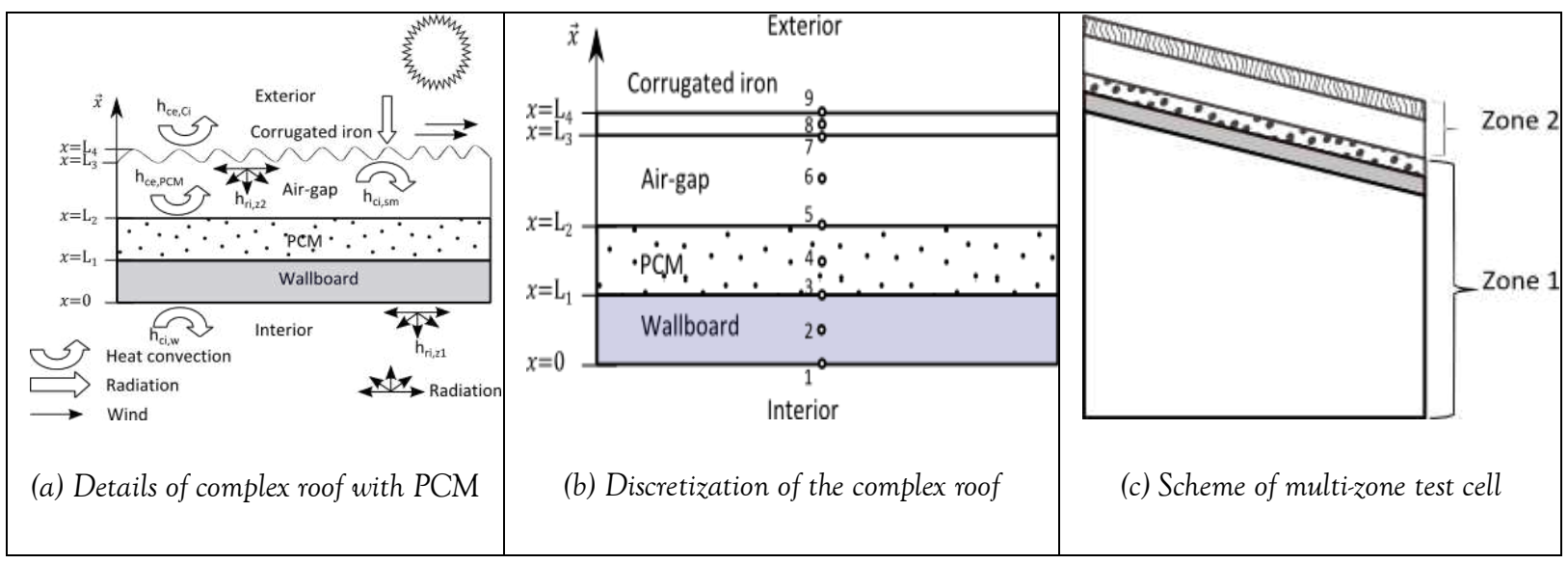

Figure 1: Presentation of studied case.

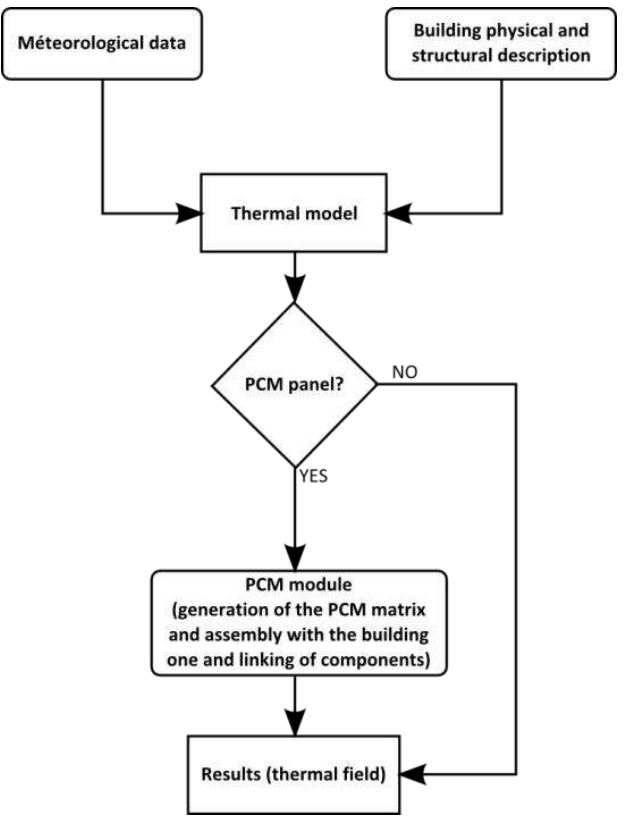

Figure 2: Integration of the PCM model to the existing ISOLAB code. 

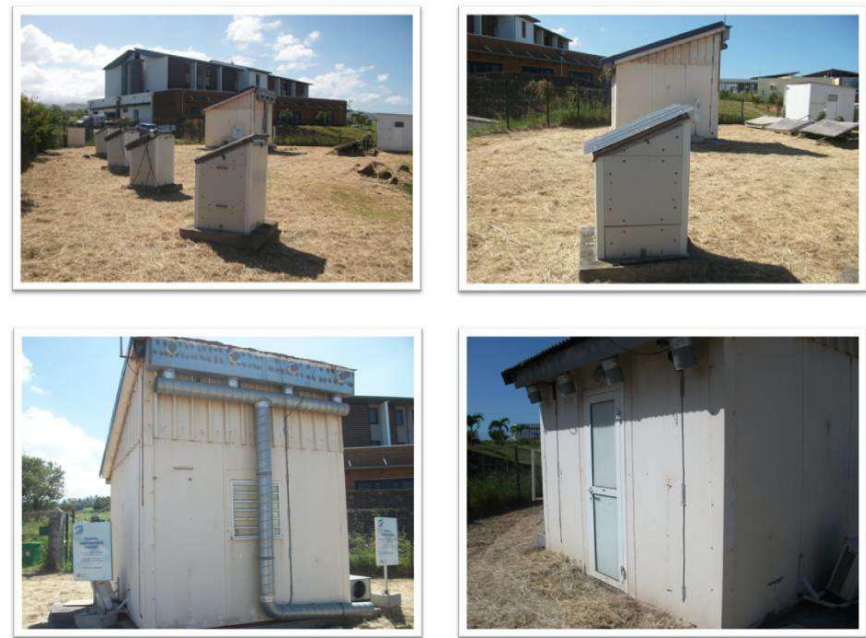

Figure 3: Photo of ISOTEST and LGI test cell

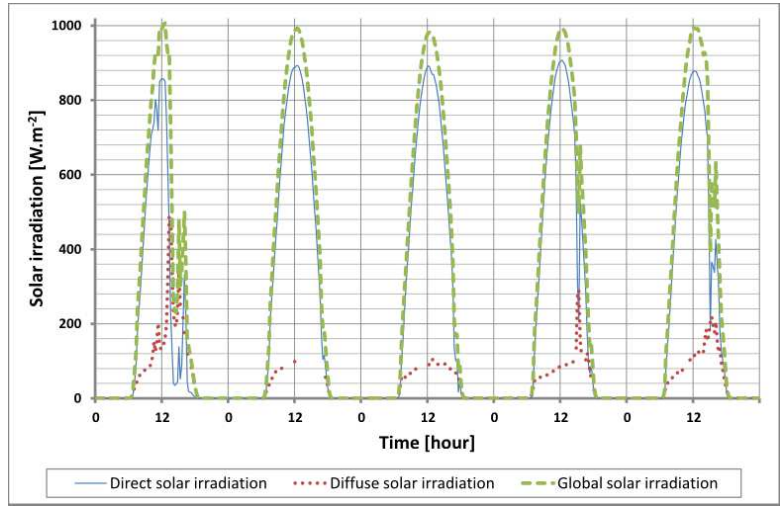

(a) Solar irradiation

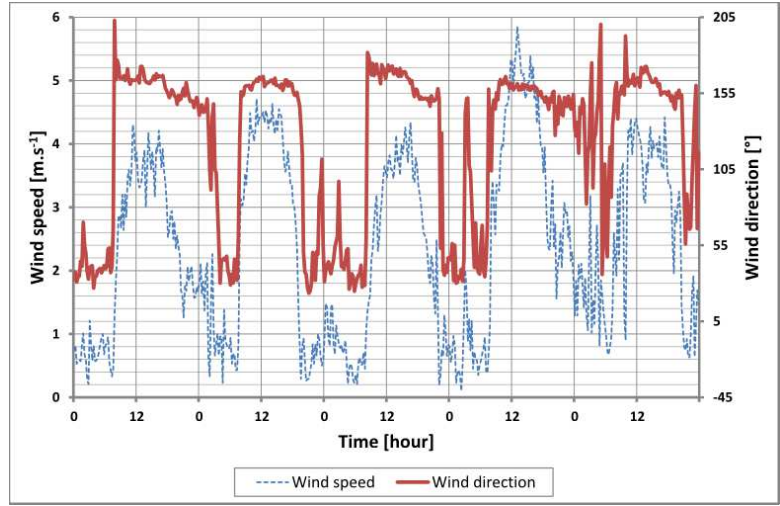

(b) Wind speed and wind direction

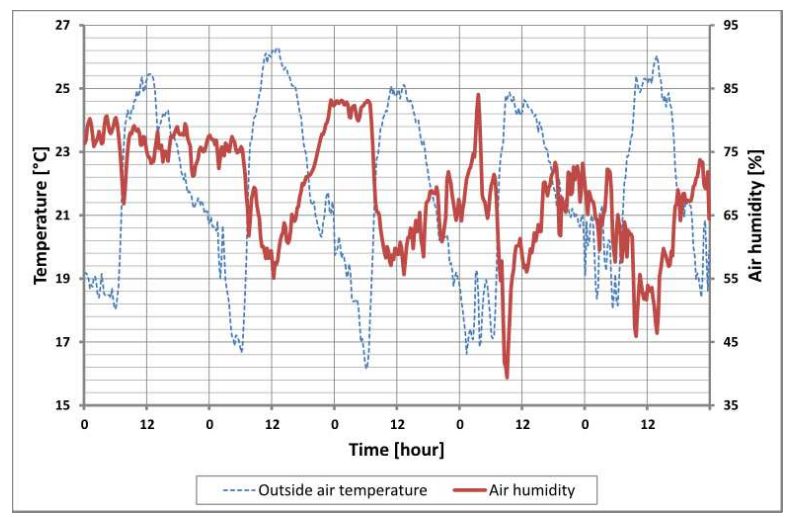

(c) Outside air temperature and air humidity

Figure 4: The climatic conditions during experimental period. 


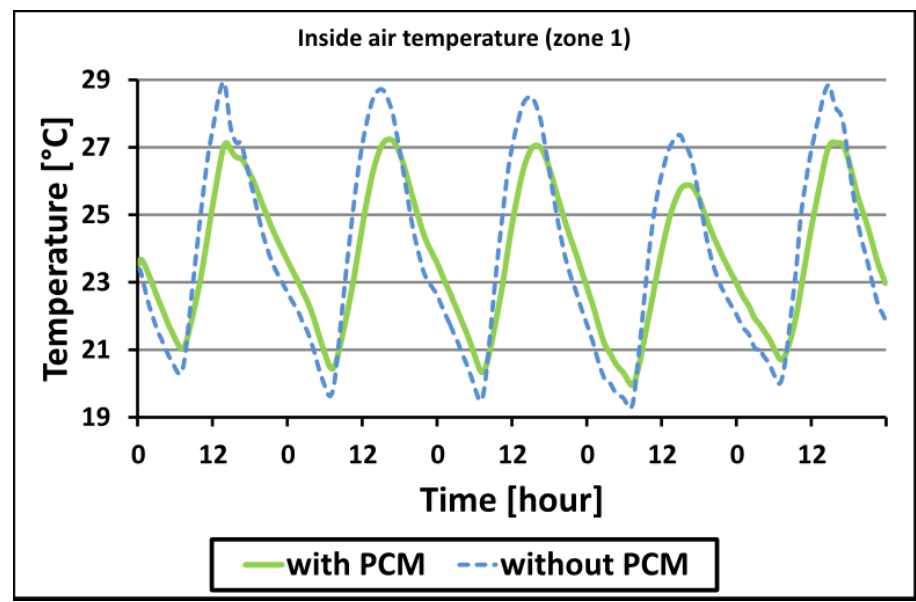

Figure 5: Thermal impact of PCM on the inside air temperature of the building.

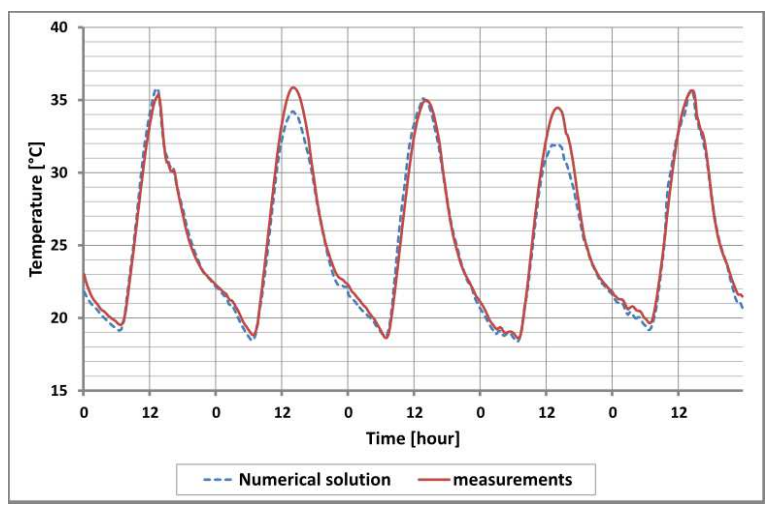

(a) Surface temperature of plasterboard

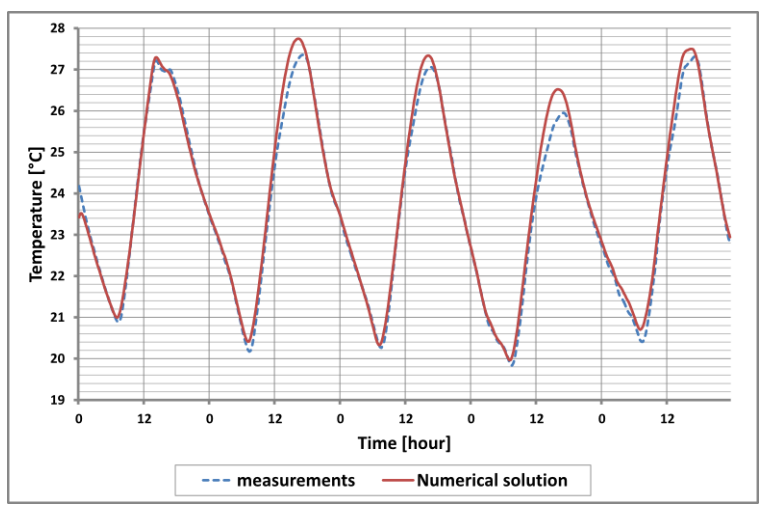

(c) Inside air temperature of test cell

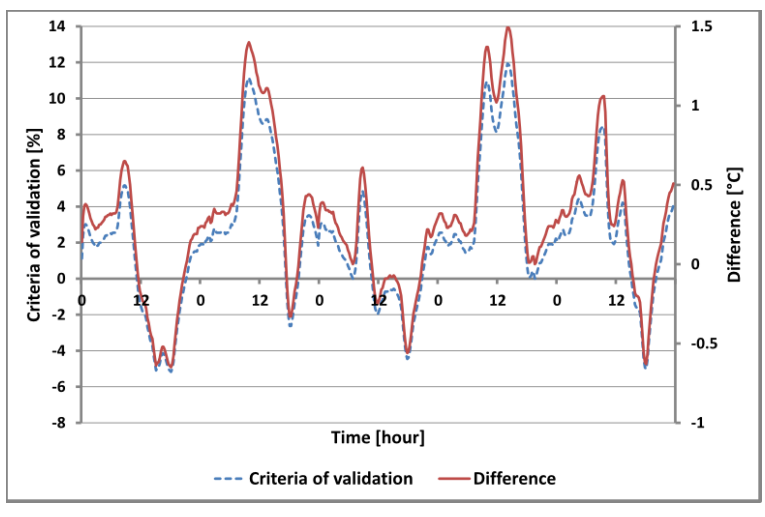

(b) Criteria validity for the temperature of plasterboard

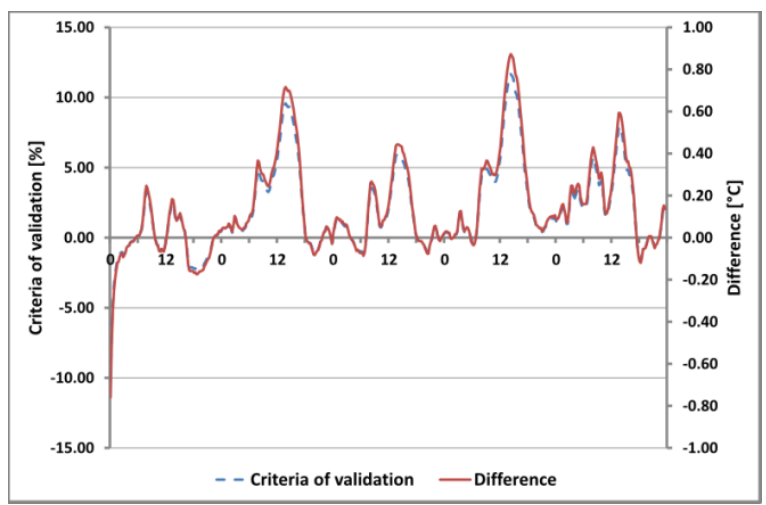

(d) Criteria validity for the inside air temperature of test cell

Figure 6: Comparison between numerical solution and experimental data for the surface temperature of plasterboard and air temperature within test cell. 


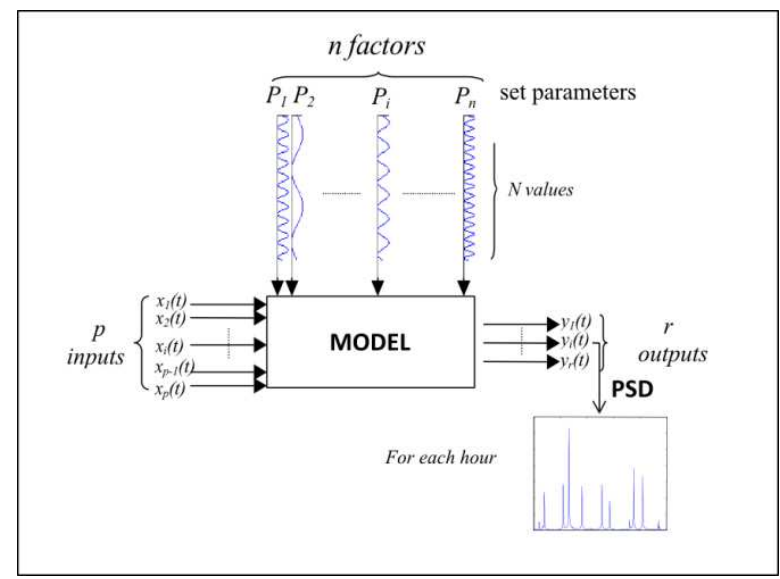

Figure 7: Procedure of sensitivity analysis.

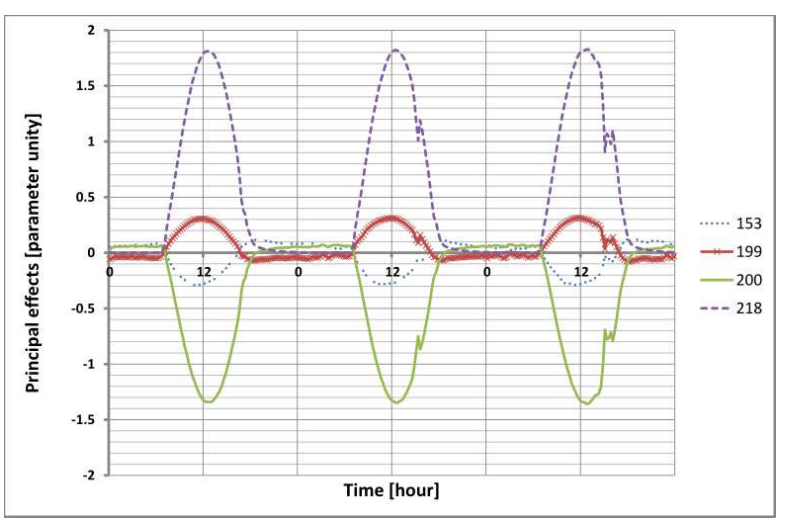

(a) Principal effects of parameters on the air-gap temperature

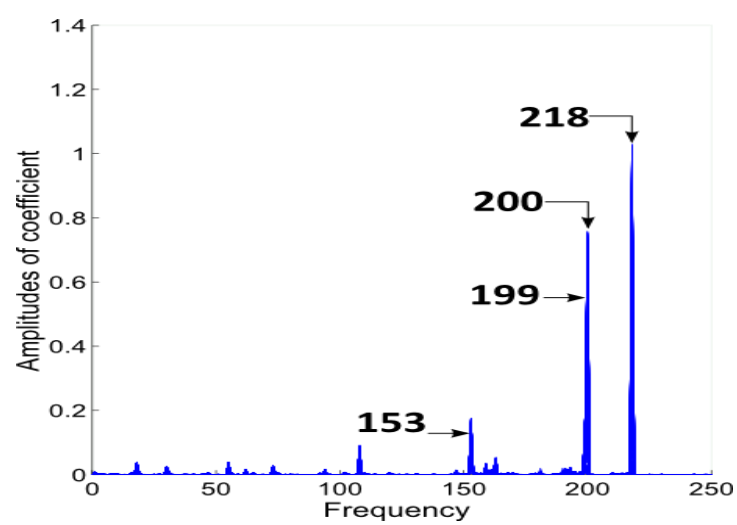

(b) Fourier spectral

Figure 8: Results of the sensitivity analysis for the air-gap temperature. 


\section{Submission of manuscript to Energy and Buildings}

\section{A thermal model for Phase Change Materials in a building roof for a tropical and humid climate: \\ Model description and elements of validation}

Stéphane GUICHARD, Frédéric MIRANVILLE, Dimitri BIGOT and Harry BOYER

Contents:

- List of tables

Corresponding author:

\section{Stéphane GUICHARD}

Physics and Mathematical Engineering Laboratory for Energy and Environment (PIMENT)

University of Reunion

117, rue du Général Ailleret

97430 Le Tampon

tél : 0693132090

fax : 0262962859

email : stephane.guichard@univ-reunion.fr 


\section{List of tables}

\begin{tabular}{|l|c|}
\hline \multicolumn{1}{|c|}{ Localization } & Reference value $\left[\mathrm{W} \cdot \mathrm{m}^{-2} \cdot \mathrm{K}^{-1}\right]$ \\
\hline Interior faces of zone 2 & 3.5 \\
\hline Side faces of zone 2 & 3.5 \\
\hline Top face of ceiling & 1 \\
\hline Bottom face of ceiling & 1 \\
\hline Faces of zone 1 & 3.5 \\
\hline
\end{tabular}

Table 1: Reference values used for the numerical simulations.

\begin{tabular}{|c|c|c|}
\hline Element & Composition & $\operatorname{Remark}(s)$ \\
\hline $\begin{array}{l}\text { Opaque vertical } \\
\text { walls }\end{array}$ & $\begin{array}{c}\text { Sandwich board } 80 \mathrm{~mm} \text { thick } \\
\text { cement-fibre / polyurethane / cement-fibre }\end{array}$ & \\
\hline Window & Aluminium frame, $8 \mathrm{~mm}$ clear glass & Blind-type $0.8 \mathrm{x} 0.8 \mathrm{~m}$ \\
\hline Glass door & Aluminium frame, $8 \mathrm{~mm}$ clear glass & $\begin{array}{l}\text { Glass in upper and lower } \\
\text { parts, } 0.7 \times 2.2 \mathrm{~m}\end{array}$ \\
\hline Roofing complex & $\begin{array}{l}\text { Corrugated galvanised steel of } 1 \mathrm{~mm} / \text { air layer of } 280 \mathrm{~mm} \\
\text { thick/PCM of } 5.26 \mathrm{~mm} \text { thick/ Plasterboard of } 12.5 \mathrm{~mm}\end{array}$ & $\begin{array}{l}\text { PCM is laminated to } \\
\text { aluminium protective } \\
\text { foils. } \\
\text { Roof inclined to } 20^{\circ}\end{array}$ \\
\hline Floor & Concrete slabs of thickness $80 \mathrm{~mm}$ on $60 \mathrm{~mm}$ thick polystyrene & \\
\hline
\end{tabular}

Table 2: Arrangement of the LGI test cell 


\begin{tabular}{|c|c|c|}
\hline \multicolumn{2}{|c|}{ Thermal properties } \\
\hline Parameter & Value & Unit \\
\hline Thermal conductivity $: \lambda_{s} /: \lambda_{l}$ & $0.22 / 0.18$ & $\mathrm{~m}^{-1} \cdot \mathrm{K}^{-1}$ \\
\hline Heat capacity $: C_{p s} / C_{p l}$ & $3134 / 2832.5$ & $\mathrm{Jg}^{-1} \cdot \mathrm{K}^{-1}$ \\
\hline Latent heat $:: L_{m}$ & 71000 & ${ }^{\circ} \mathrm{C}$ \\
\hline Melt temperature $: T_{m}$ & 23.4 & $\mathrm{~mm}$ \\
\hline Thickness & Descriptive properties & $\mathrm{mm}$ \\
\hline Width & 5.26 & $\mathrm{~mm}$ \\
\hline Length & 1000 & \\
\hline
\end{tabular}

Table 3: Characteristics of PCM used

\begin{tabular}{ll}
\hline Frequency & Parameters \\
\hline 153 & Plasterboard surface \\
199 & Inside convective exchange coefficient of the corrugated iron \\
200 & Outside convective exchange coefficient of the corrugated iron \\
218 & Absorptivity coefficient of the metal sheet \\
\hline
\end{tabular}

Table 4: Most influential parameters on the air-gap temperature. 


\begin{tabular}{ll}
\hline Frequency & Parameters \\
\hline $103\left(\mathrm{~h}_{\mathrm{ci}, f l o o r}\right)$ & Inside convective exchange coefficient of the floor (zone 1) \\
$107\left(\mathrm{~h}_{\mathrm{ci}, \mathrm{w}}\right)$ & Inside convective exchange coefficient of the wallboard \\
$108\left(\mathrm{~h}_{\mathrm{ci}, \mathrm{PCM}}\right)$ & Outside convective exchange coefficient of the PCM panel \\
154 & $\begin{array}{l}\gamma \text { coefficient } \\
199\left(\mathrm{~h}_{\mathrm{ci}, \mathrm{sm}}\right)\end{array}$ \\
$200\left(\mathrm{~h}_{\mathrm{ce}, \mathrm{Ci}}\right)$ & Onside convective exchange coefficient of the metal sheet \\
$200\left(\alpha_{\mathrm{Ci}}\right)$ & Absorptivity coefficient of the metal sheet
\end{tabular}

Table 5: Most influential parameters at the end of sensitivity analysis. 